Accepted for publication in Archives of Sexual Behavior, June 2020

\title{
Gender Nonconformity of Bisexual Men and Women
}

Gerulf Rieger $^{1}$, Luke Holmes ${ }^{1}$, Tuesday M. Watts-Overall ${ }^{2}$, Dragos C. Gruia ${ }^{1}$, J. Michael Bailey ${ }^{3}$ \& Ritch C. Savin-Williams ${ }^{4}$

1. Department of Psychology, University of Essex

2. School of Psychology, University of East London

3. Department of Psychology, Northwestern University, Chicago

4. Department of Psychology, Cornell University

\begin{abstract}
The degree to which bisexual-identified individuals are distinct from either heterosexual or homosexual individuals in their sexual orientation is an ongoing debate. We examined potential differences between these groups with respect to a strong correlate of sexual orientation, gender nonconformity (femininity in males, masculinity in females). Across pooled data, we compared self-reports of childhood gender nonconformity $(\mathrm{n}=919)$ and adulthood gender nonconformity $(n=1265)$, and observer ratings of adulthood gender nonconformity $(n=915)$ between sexual orientations. Most analyses suggested a steady increase in gender nonconformity from exclusively heterosexual to exclusively homosexual. However, in some analyses, bisexual men were closer to homosexual men than to heterosexual men in their gender nonconformity. The intermediate status of bisexual people in gender nonconformity was not due to the sample having a mixture of very gender-conforming and very gender-nonconforming individuals. In total, men and women with bisexual orientations appeared neither like heterosexual nor homosexual individuals, at least with respect to their gender-related traits.
\end{abstract}

Keywords: sexual orientation; gender nonconformity; bisexuality; sex differences 


\section{INTRODUCTION}

On average, homosexual men are more feminine than heterosexual men, and homosexual women are more masculine than heterosexual women, in their behaviors, activities, and interests. These differences become distinct in early childhood (Rieger, Linsenmeier, Gygax, \& Bailey, 2008). Given this pattern, homosexual people are described as more gender nonconforming than heterosexual people. In one meta-analysis, homosexual men and women recalled more gendernonconforming childhood behaviors and activities than heterosexual men and women, and these effects were large with Cohen's d's of 1.31 and 0.96, respectively (Bailey \& Zucker, 1995). In another meta-analysis, homosexual men and women reported more gender nonconforming interests and self-concepts in adulthood than heterosexual men and women. These effects were also large with median Cohen's d's 0.94 and 1.37, respectively (Lippa, 2005). Moreover, others perceive homosexual people as more gender nonconforming than heterosexual people, even if they observe them for only a few seconds. Evaluations of gender nonconformity are based on a combination of observed motor behaviors, speech patterns, physical appearance, and expressed interests (Johnson, Gill, Reichman, \& Tassinary, 2007; Rieger, Linsenmeier, Gygax, Garcia, \& Bailey, 2010). These evaluations by others relate modestly to strongly to a person's selfdescribed sexual orientation, median Cohen's $d=1.35$, and correspond with self-reported gender nonconformity, median $r=.41$ (Rieger et al., 2008; 2010).

The majority of past work concentrated on differences in gender nonconformity between heterosexual and homosexual individuals. However, because of the strong general link of masculinity-femininity with sexual attractions to females or males, the study of gender nonconformity could potentially be applied to the expression of sexual orientation in less 
commonly studied and less understood groups. The present research focused on individuals who report varied degrees of bisexual orientations.

Depending on measure and study, $87 \%$ to $96 \%$ of the population report heterosexual identities, feelings, and activities. The remaining men are more likely to identify as homosexual than bisexual, and remaining women more likely to identify as bisexual than homosexual (Gates, 2011; Savin-Williams \& Vrangalova, 2013). Yet, especially for males, it is debatable whether those who identify as bisexual are, in fact, bisexual, at least in regards to their physiological sexual arousal towards men and women. This is due to the assessment that most men have strong sexual responses to one sex only, whereas bisexual arousal is neither common nor necessarily seen in men with bisexual identities (Bailey, 2009). In some studies bisexual-identified men were only aroused to males, similar to homosexual men (Rieger, Chivers, \& Bailey, 2005); in other studies bisexual men showed bisexual arousal (Rosenthal, Sylva, Safron, \& Bailey, 2012; Slettevold et al., 2019); yet, other analyses suggested that a bisexual identity encompasses different types of men, showing either bisexual, heterosexual, or homosexual arousal (Hsu, Rosenthal, Miller, \& Bailey, 2016; Slettevold et al., 2019).

Bisexual identities are more common among women than men (Savin-Williams \& Vrangalova, 2013). Moreover, unlike most men, most women show physiological sexual response to both males and females, regardless of their identity as heterosexual, bisexual, or homosexual (Chivers, 2017; Rieger, Savin-Williams, Chivers, \& Bailey, 2016). Thus, unlike men, women's sexual orientation is weakly reflected in their arousal patterns. This sex difference in physiological sexual response possibly explains why discussions on whether bisexual individuals are different from heterosexual or homosexual individuals have concentrated on men (Bailey, 2009). 
A further understanding of the distinctiveness of bisexual individuals could come from examining their level of gender nonconformity. In previous self-report studies, bisexual women were neither similar to heterosexual nor homosexual women in their gender nonconformity but, rather, had intermediate levels (Lippa, 2005, 2008, 2020). Bisexual men may also report intermediate degrees of gender nonconformity between heterosexual and homosexual men (Cohen, 2002; Lippa, 2005, 2020). Further, in the views of heterosexual and homosexual people, bisexual men and women are intermediate in their gender nonconformity (Burke \& LaFrance, 2016a). However, bisexuals' intermediate levels are not always found. In other work, bisexual men self-reported gender nonconformity levels more similar to homosexual men than heterosexual men (Lippa, 2008). Or, unlike the views of other people, bisexual men and women viewed their own sexual identity as between heterosexual and homosexual groups in gender nonconformity, but closer to heterosexual groups (Burke \& LaFrance, 2016b). Likewise, in other work, bisexual men were more likely to report gender-related traits similar to heterosexual men than homosexual men (Kahn \& Halpern, 2019). Because self-reports of gender nonconformity might be biased due to social desirability (Gottschalk, 2003; but see rebuttal by Zucker, 2005), it is possible that bisexual people as a group do not fully acknowledge their level of gender nonconformity, whereas other people view them as different from heterosexual individuals, that is, as more gender conforming, as compared to how they view themselves.

Because of these inconsistent findings, we examined several competing hypotheses. First, given past work on self-report, bisexual individuals may be between heterosexual and homosexual individuals in their gender nonconformity (Fig. 1A). Second, corresponding with some work on bisexual men's sexual arousal patterns, bisexual individuals could be similar to homosexual individuals, especially if they are male (Fig. 1B). Third, given other past work, 
bisexual individuals could be closer to heterosexual than homosexual individuals, but perhaps more so in their self-reports than when evaluated by others (Fig. 1C).

As noted previously, bisexual men might comprise a mixture of men with heterosexual, homosexual, and bisexual arousal patterns (Hsu et al., 2016; Slettevold et al., 2019). Thus, if bisexual identities encompass individuals who are either similar in their gender nonconformity to heterosexual individuals (low average gender nonconformity) or to homosexual individuals (high average gender nonconformity), then variance in gender nonconformity should be higher in bisexual-identified persons as compared with heterosexual and homosexual persons. In one study, a visual inspection of self-reported gender nonconformity did not support this prediction. Instead, both bisexual and homosexual groups appeared more variant than heterosexual groups (Lippa, 2008). Still, especially in males, it is possible that a systematic comparison would show increased variability of gender nonconformity in those who identify as bisexual as compared to those who identify as heterosexual or homosexual, analogous to previous findings for their physiological sexual responses (Fig. 2).

A related issue concerns men and women who identify as almost-exclusively (or mostly) heterosexual, and those who identify as almost-exclusively (or mostly) homosexual. (Vrangalova \& Savin-Williams, 2012). Mostly heterosexual men are more sexually aroused to women than men, but still responded more strongly to both sexes than exclusively heterosexual men (Jabbour, Hsu, \& Bailey, 2020; Savin-Williams, Rieger, \& Rosenthal, 2013). Corresponding differences in the arousal patterns between mostly homosexual and exclusively homosexual men are not always statistically significant, but in the predicted direction of mostly homosexual men appearing more bisexual (Savin-Williams, Cash, McCormack, \& Rieger, 2017; Savin-Williams et al., 2013; Semon, Hsu, Rosenthal, \& Bailey, 2017). 
If distinctions between individuals with exclusive and almost exclusive sexual orientations are valid, they could be confirmed with respect to gender nonconformity. For example, mostly heterosexual individuals could be more gender nonconforming than exclusively heterosexual individuals, and mostly homosexual individuals less gender nonconforming than exclusively homosexual individuals. Those with equal bisexual preferences may fall between mostly heterosexual and mostly homosexual people (Fig. 3A). However, it could also be that mostly heterosexual and mostly homosexual individuals are close to those with equal bisexual preferences, and fall, just like bisexual individuals, between exclusively heterosexual and exclusively homosexual individuals in their gender nonconformity (Fig. 3B). Yet, it is also possible that exclusive groups and adjunct almost exclusive groups do not differ at all in their gender nonconformity. That is, exclusively heterosexual and mostly heterosexual individuals may not differ in their gender conformity, and exclusively homosexual and mostly homosexual individuals may not differ in their gender nonconformity, whereas bisexual individuals fall between these other groups (Fig. 3C). At least in women, the latter pattern was found with respect to the probability of their gender-atypical traits in adulthood (Kahn \& Halpern, 2019).

\section{The Present Study}

We analyzed the expression of gender nonconformity across sexual orientations with three measures derived from unpublished data pooled with published data (Rieger et al., 2008; 2010; 2016; Rosenthal et al., 2012). This resulted in large samples for self-reported (recalled) childhood gender nonconformity $(\mathrm{n}=919)$, self-reported adulthood gender nonconformity $(\mathrm{n}=$ 1265), and observer-rated adulthood gender nonconformity $(n=915)$. By merging these data, analyses offered better information on the magnitude of the effect of sexual orientation on gender 
nonconformity. Moreover, unlike the majority of previous work, analyses focused on men and women with varied degrees of bisexual orientations.

In sum, and based on the previously reviewed literature, we first tested the following competing hypotheses:

1A. Bisexual people are intermediate between heterosexual and homosexual people in their gender nonconformity (Fig. 1A).

1B. Or, bisexual people are closer to homosexual than heterosexual people in their gender nonconformity. This pattern may characterize men more than women (Fig. 1B).

1C. Or, bisexual people are closer to heterosexual than homosexual people in their gender nonconformity, and more so in their self-report than when viewed by others (Fig. 1C).

Our next hypothesis regarded variation of gender nonconformity:

2. Bisexual people show more variation than heterosexual and homosexual people in gender nonconformity, especially in men (Fig. 2).

Finally, we tested the following competing hypotheses:

3A. Mostly heterosexual individuals are between heterosexual and bisexual individuals, and mostly homosexual individuals are between bisexual and homosexual individuals in their gender nonconformity (Fig. 3A).

3B. Or, mostly heterosexual and mostly homosexual individuals are different from exclusively heterosexual and exclusively homosexual individuals, but similar to bisexual individuals in their gender nonconformity (Fig. 3B).

3C. Or, exclusively heterosexual and mostly heterosexual individuals do not differ in their gender conformity, and exclusively homosexual and mostly homosexual individuals do not differ in gender nonconformity, but bisexual individuals are between these groups (Fig. 3C). 


\section{METHOD}

\section{Participants}

We recruited participants in different studies over 15 years and at two locations in North America and one in the United Kingdom. A total of 654 men and 611 women reported their sexual orientation identities on a Kinsey scale (Kinsey, Pomeroy, \& Martin, 1948). A score of 0 or 1 corresponds with an exclusive or almost-exclusive heterosexual orientation, scores of 2, 3, and 4 with bisexual orientations (more towards the other sex, equal, more towards the same sex), and a score of 5 or 6 with an almost-exclusive or exclusive homosexual orientation. Table 1 shows sexual orientation identities by age, ethnicity, and education. The distribution of sexual orientations appeared more bimodal in men than women, and particularly in men, bisexuality with equal preferences (Kinsey score 3) was the least common. This mirrors to some degree sex differences in distributions of sexual orientations in nationally representative samples (SavinWilliams \& Vrangalova, 2013).

Individual studies that contributed to the present research were conducted independently of each other (Rieger et al., 2008; 2010; 2016; Rosenthal et al., 2012). Therefore, not all participants provided data across all measures for present analyses. Furthermore, we combined published data with previously unpublished data. All 654 men and all 611 women self-reported adulthood gender nonconformity. For self-recalled childhood nonconformity, data from 525 men and 394 women were available. For observer-rated adulthood gender nonconformity, we had data from 457 men and 458 women. A subset of 291 men and 297 women provided data for all three measures of gender nonconformity.

In addition, psychology students participated as raters of gender nonconformity for course credit. Each video-recorded target participant was evaluated by a minimum of 20 and a 
maximum of 80 male and female raters who were either heterosexual or nonheterosexual. Because targets were video-recorded and rated in different sets, not all raters viewed all targets. In total, we had 110 heterosexual male raters, 101 nonheterosexual male raters, 125 heterosexual female raters, and 102 nonheterosexual female raters.

In one data set of 228 target participants, we had additional observer ratings of their masculinity and, independently, of their femininity. These ratings were conducted by a group of 80 male and female raters who were either heterosexual or nonheterosexual. These additional ratings were used for further analyses, as described below.

\section{Measures}

Sexual Orientation. Participants reported their sexual orientation identities in addition to their sexual attraction towards men and women on 7-point scales (Kinsey et al., 1948). Measures were correlated for both sexes, $p$ 's $<.0001, .93<r$ 's $<.98, .90<95 \%$ CI's $<.99$, and averaged within participants. For this composite, a score of 0 represented exclusive heterosexuality, a score of 3 bisexuality with equal preferences, and a score of 6 exclusive homosexuality. This composite was used as a continuous measure of sexual orientation in analyses.

Gender Nonconformity. The Childhood Gender Nonconformity Scale measured self-reported gender nonconformity during childhood with 7 items for each sex (Rieger et al., 2008). Example statements are, "As a child, I preferred playing with girls rather than boys" for men, and, "As a child, I often felt that I had more in common with boys than girls" for women. Gender nonconformity in adulthood was assessed with seven items for each sex with the Continuous Gender Identity Scale (Rieger et al., 2008). Example statements are, "My mannerisms are more feminine than those for most men of my age" for men, and "I assume most people see me as more masculine than other women" for women. Items were endorsed on 7-point scales, with 
higher scores representing higher levels of gender nonconformity. For both men and women, item reliability (Cronbach's $\alpha$ ) exceeded .80 for both childhood and adulthood measures.

\section{Procedure}

Target Participants. All participants provided written informed consent and completed a survey on their demographics, sexual orientation, and gender nonconformity. Where applicable, participants were video-recorded for 5 to 20 minutes. Participants sat in a chair in front of a white wall and had their whole body recorded in order to capture their gestures and movements. For the purpose of our analyses, we used their responses to a neutral question, which inquired about the state of the weather where they lived. When editing these videos, we selected the first complete sentence that interviewees articulated within the first 20 seconds of their answer, with a minimum length of 6 seconds. If participants' response was less than 6 seconds, we used a combination of the first and the second sentence. The majority of selected videos were approximately 10 seconds long. Previous research indicates that raters can reliably assess behavioral traits linked to sexual orientation from such short videos (Tskhay \& Rule, 2013). Raters. Videos were presented in the software Inquisit. Videos for male and female target participants were kept separate and split into 9 sets of male and 9 sets of female targets. To avoid rater fatigue, each rater was limited to one hour of evaluations and never viewed more than 60 targets. Raters viewed, in counterbalanced order, one set of male targets and one set of female targets. They were not told that they viewed targets of different sexual orientations.

Raters indicated their impression of each target's appearance and demeanor by comparing each target to the average person of the target's sex and age. For example, after each video of a man, they were told to "rate whether this man appeared or behaved in a more feminine or masculine way." Ratings were completed on 7-point scales. For videos of males, a score of 1 
was "more masculine," 4 "average," and 7 "more feminine." A reversed scale was used for ratings of females. Thus, for both sexes, 7 represented maximum gender nonconformity.

Additional raters evaluated targets on masculinity or, independently, femininity. For ratings of masculinity, the wording was "rate how masculine is this person" and the scale ranged from 1 "not at all masculine" to 4 "average" to 7 "very masculine". For ratings of femininity, the scale ranged from 1 "not at all feminine" to 4 "average" to 7 "very feminine". These additional raters evaluated targets on only one of these scales.

Across videos, average evaluations of the four rater groups (heterosexual and nonheterosexual men and women) correlated with each other, $p$ 's $<.0001, .71<r$ 's $<.95, .49<$ 95\% CI's <.97. Across all raters, inter-rater reliability (Cronbach's $\alpha$ ) exceeded .96 for each target sex. Hence, for each video, an average gender nonconformity score was computed across all raters. Likewise, additional ratings of masculinity and of femininity were highly reliable across raters (Cronbach's $\alpha$ 's $>.90$ ) and averaged for each video to achieve an average score of the targets' masculinity and, independently, of their femininity.

\section{RESULTS}

\section{Correlations}

We examined correlations between measures of gender nonconformity. In men, the correlations of self-reports from childhood and adulthood were significant, $p<.0001, r=.62$, $95 \%$ CI $[.56, .67]$, and so were the correlations of observer-ratings with self-reports from childhood, $p<.0001, r=.45[.35, .54]$, and adulthood, $p<.0001, r=.49[.42, .56]$. In women, these correlations were also significant, $p<.0001, r=.58[.51, .64], p<.0001, r=.41[.31, .50]$, and $p<.0001, r=.49[.42, .56]$, respectively. We reexamined these relationships after partialling out the effects of sexual orientation (which we expected to contribute). That is, we computed the 
partial correlation between variables of gender nonconformity, controlling for participants' Kinsey scores. Although weaker in effect, in men these correlations remained significant, $p<$ $.0001, r=.45[.39, .51], p=.0002, r=.20[.09, .30]$, and $p<.0001, r=.41[.33, .50]$, respectively. Likewise, in women these correlations remained significant, $p<.0001, r=.51[.42$, $.59], p<.0001, r=.33[.22, .45]$, and $p<.0001, r=.36[.28, .45]$, respectively. For these correlations, we computed a composite score of gender nonconformity for those men $(n=291)$ and women $(n=297)$ from whom all three measures were taken. For these men and women, reliability (Cronbach's $\alpha$ 's) of each measure was between .82 and .98 . We used the composite score of gender nonconformity in some analyses.

\section{Hypotheses 1A-1C}

Hypothesis 1A was that bisexual participants (with Kinsey score 3 representing bisexuality with equal preferences) would be between heterosexual (Kinsey score 0 ) and homosexual participants (Kinsey score 6) in their gender nonconformity. Alternatively, Hypothesis 1B was that, especially in males, bisexual participants are closer to homosexual than heterosexual participants in their gender nonconformity. In contrast to Hypothesis $1 \mathrm{~A}$ and $1 \mathrm{~B}$, Hypothesis 1C was that bisexual individuals are closer to heterosexual than homosexual individuals in their gender nonconformity, especially in their self-report (Figs. 1A-C). We tested for these competing hypotheses simultaneously by conducting regression analyses, split by sex. The dependent variable was either self-report regarding childhood or adulthood, or observerrated adulthood gender nonconformity. We regressed each measure of gender nonconformity onto the linear and quadratic effects of sexual orientation. If bisexual participants are intermediate to heterosexual and homosexual participants in their gender nonconformity, then only the linear effect should be significant. If bisexual participants were closer to homosexual 
than heterosexual participants in their gender nonconformity, then the linear effect should be qualified by a negative quadratic effect. If bisexual individuals were closer to heterosexual than homosexual individuals, the linear effect would be qualified by a positive quadratic effect.

In these regression analyses, we further tested for cubic effects of sexual orientation on gender nonconformity, relevant for Hypotheses 3A-3C on mostly heterosexual and mostly homosexual participants (see below). In the present section, however, we focused on bisexual individuals, in general, and on the linear and quadratic effects.

On average, bisexual participants were, in a linear fashion, between heterosexual and homosexual participants in their gender nonconformity (Figs. 4 and 5). The linear effects of sexual orientation were significant across measures of gender nonconformity and for both sexes, $p$ 's $\leq .001, .28<\beta$ 's $<.71, .18<95 \%$ CI's $<.93$. (The effect size is the standardized regression coefficient, $\beta$, with its $95 \%$ confidence intervals. For change in $\mathrm{R}^{2}, \Delta R^{2}$, and stationary points of significant curvilinear effects within the range of data, see figures.) For men's self-reports from childhood and adulthood, the linear effects were qualified by negative quadratic effects because bisexual men were closer to homosexual than heterosexual men in their gender nonconformity, $p$ $=.003, \beta=-.18[-.29,-.06$, and $p=.0001, \beta=-.23[-.35,-.11]$, respectively (Figs. 4A and 4B). In women, no quadratic effects were significant, $p$ 's $\geq .27, .05<\beta$ 's $<.06,-.10<95 \%$ CI's $<.19$.

We then examined these patterns in participants for whom a composite score of gender nonconformity was available. Given the significant linear effects of sexual orientation on gender nonconformity, bisexual men and women were in their overall gender nonconformity between heterosexual and homosexual men and women, $p<.0001, \beta=.57[.48, .66]$ and $p<.0001, \beta=$ $.47[.37, .58]$, respectively. In men, this linear effect was qualified by a negative quadratic effect because bisexual men were more similar to homosexual than heterosexual men in their gender 
nonconformity, $p=.008, \beta=-.22[-.38,-.06]$ (Fig. 6A). A significant quadratic effect was not found in females, $p=.93, \beta=-.01[-.16, .14]$ (Fig. 6B).

Next, we examined these patterns for 228 participants for whom we had additional observer ratings of masculinity and femininity. These two ratings were highly and negatively correlated in men, $p<.0001, r=-.93[-.95,-.90]$, and women, $p<.0001, r=-.97[-.98,-.96]$. Moreover, both in their rated masculinity and their rated femininity, bisexual men and women were in a linear fashion between heterosexual and homosexual participants (Figs. 7 and 8).

\section{Hypothesis 2}

We examined whether bisexual participants had greater variance in gender nonconformity compared with heterosexual and homosexual participants (Fig. 2). We had speculated that this may be especially the case in males. To test sexual orientation differences in variability, we computed for each measure of gender nonconformity the absolute residuals of the effects shown in Figs. 4 to 6 . We regressed these absolute residuals onto the participants' sexual orientation with an interest in a quadratic effect. (For consistency with our other analyses, we also tested for cubic effects even though Hypothesis 2 did not require such a test.) If bisexual participants are more variable than heterosexual or homosexual participants, their absolute residuals should be larger than other groups' absolute residuals, resulting in a significant negative quadratic effect. In females, this was not the case for any measure of gender nonconformity, $p$ 's $\geq .15,-.11<\beta$ 's $<.06,-.26<95 \%$ CI's $<.19$. In males, one significant negative quadratic effect was found for self-reported childhood gender nonconformity, $p=.002$, $\beta=-.22[-.36, .09]$. This significant quadratic effect was found in addition to a significant linear effect, $p<.0001, \beta=.24[.16, .32]$. In combination, these effects indicated that both bisexual and homosexual men were more variable in their childhood gender nonconformity than heterosexual 
men (Fig. 9A). Further, in four of the six analyses across men and women, there was a significant linear increase from heterosexual, to bisexual, to homosexual, in the variability in gender nonconformity. This meant that, in general, variability was most common among exclusively homosexual individuals (Figs. 9 and 10).

For participants with a composite score of gender nonconformity across the three measures, a similar pattern was found. As they reported increased homosexual orientations, their variability in gender nonconformity increased in a linear fashion, $p<.0001, \beta=.26[.15, .37]$, and $p=.002, \beta=.19[.07, .30]$, for males and females, respectively. For males but not for females, this linear effect was further qualified by a significant negative quadratic effect, $p=$ $.009, \beta=-.26,[-.45,-.07]$, and $p=.89, \beta=.01[-.15, .18]$, respectively. This was due to the finding that both bisexual and homosexual men were more variable than heterosexual men, whereas in women, variability was greatest among homosexual individuals (Fig. 11).

\section{Hypothesis 3}

We next examined the degree to which mostly heterosexual and mostly homosexual individuals were similar to, or different from, exclusively heterosexual, bisexual, and exclusively homosexual individuals. Specifically, we examined the cubic effect of sexual orientation on gender nonconformity. The presence, absence, and shape of the cubic effect informed in different ways. If Hypothesis $3 \mathrm{~A}$ was confirmed, no cubic effect would qualify the linear effect of sexual orientation on gender nonconformity. In this scenario, mostly heterosexual participants would be between exclusively heterosexual and bisexual participants in their gender nonconformity, and mostly homosexual participants would be between exclusively homosexual and bisexual participants (Fig. 3A). 
If Hypothesis 3B was confirmed, mostly heterosexual participants (Kinsey score 1) would be substantially more gender nonconforming than exclusively heterosexual participants (Kinsey score 0), and close to bisexual participants (Kinsey scores 2-4). Correspondingly, mostly homosexual participants (Kinsey score 5) would be substantially less gender nonconforming than exclusively homosexual participants (Kinsey score 6), and close to bisexuals (Kinsey scores 2-4). In this case, a positive cubic effect would be detected (Fig. 3B).

If Hypothesis 3C was confirmed, exclusively heterosexual participants (Kinsey score 0) should be equal to mostly heterosexual participants (Kinsey score 1) in gender nonconformity. Likewise, mostly homosexual participants (Kinsey score 5) could be equal to exclusively homosexual participants (Kinsey score 6). The actual difference in gender nonconformity would only show between mostly heterosexual (Kinsey score 1), bisexual (Kinsey scores 2-4), and mostly homosexual (Kinsey score 5) participants. In this scenario, a negative cubic effect of sexual orientation on gender nonconformity would be detected (Fig. 3C).

In the computed regression analyses, we tested for the cubic effect of sexual orientation on gender nonconformity (Figs. 4-6). In one analysis, a significant, negative cubic effect was found because mostly heterosexual women were similar in their observer-rated gender nonconformity to exclusively heterosexual women, and mostly homosexual women were similar to exclusively homosexual women, $p=.04, \beta=-.14[-.27,-.01]$ (Fig. 5C). Also notable was that in their overall gender nonconformity, mostly heterosexual men were closer to bisexual than to heterosexual men, which resulted in a near-significant, positive cubic effect, $p=.08, \beta=.21[-$ $.02, .44]$ (Fig. 6A). Across analyses, though, the linear effects were the strongest in magnitude, indicating a steady increase in gender nonconformity from exclusively heterosexual to exclusively homosexual. 


\section{Variations by Demographics and Datasets}

We next examined whether the results were affected by measured demographics. In men, age correlated negatively with self-reported and observer-rated adulthood gender nonconformity, $p<.0001, r=-.19[-.26,-.11]$, and $p=.02, r=-.11[-.20,-.02]$. A non-white ethnicity related to increased levels of self-reported adulthood gender nonconformity, $p=.04, r=.09[.00, .17]$. Education correlated positively with recalled childhood gender nonconformity, $p=.03, r=.12$ $[.02, .23]$. In women, age correlated positively with self-reported and observer-rated adulthood gender nonconformity, $p=.02, r=.10[.02, .18]$, and $p=.0005, r=.16[.07, .25]$, and education positively with self-reported adulthood gender nonconformity, $p=.02, r=.12[.02, .21]$. These correlations were weak in magnitude and had little influence on the findings shown in Figs. 4-11. For example, for men's recalled childhood gender nonconformity, linear, quadratic, and cubic effects remained identical before and after controlling for all of these demographics, $p<.0001, \beta$ $=.50[.27, .75], p=.003, \beta=-.18[-.29,-.06]$, and $p=.64, \beta=.04[-.13, .21]$, versus $p=.0008, \beta$ $=.47[.22, .77], p=.002, \beta=-.18[-.30,-.07]$, and $p=.52, \beta=.05[-.12, .23]$. Hence, measured demographics did not substantially affect findings.

Our next analyses regarded whether the relationships of sexual orientation with gender nonconformity varied by data sets. We repeated the aforementioned models in which linear, quadratic, and cubic effects of sexual orientation predicted gender nonconformity. We further included a predicting variable that defined data sets, plus interactions of linear and curvilinear effects with data set. Data set did not significantly moderate linear and curvilinear effects of sexual orientation. We further computed more parsimonious regression analyses, which included only the linear effect of sexual orientation, data set, and their interaction as predictors of gender nonconformity. In these analyses, the interaction of sexual orientation with data set was 
significant for self-reported adulthood gender nonconformity in men and women, $p=.0002, \beta=$ $-.27,95 \%$ CI $[-.41,-.13]$ and, $p=.02, \beta=-.18$ [-.33, -.03] respectively. In men, this was because the effect of sexual orientation on reported adulthood gender nonconformity were not significant in two sets, $p=.21, \beta=.18[-.11, .46]$ (Rieger et al., 2010) and, $p=.68, \beta=.04[-.16, .23]$ (previously unpublished data from Rosenthal et al., 2012). Yet, this effect was significant with varied magnitude in all other sets, $p$ 's $\leq .003, .29<\beta$ 's $<.60, .11<95 \%$ CI's $<.78$.

In women, the interaction of sexual orientation with data set was due to the finding that the linear effect of sexual orientation on reported adulthood gender nonconformity was marginally significant in one set, $p=.06, \beta=.28[-.01, .58]$ (Rieger et al., 2008), and significant with varied magnitude in all other data, $p$ 's $\leq .03, .32<\beta$ 's $<.55, .03<95 \% \mathrm{CI}$ 's $<.79$. The meaning of these variations is unclear (e.g., addition analyses did not suggest that they were due to systematic differences by country or study year). Furthermore, controlling for the interaction of sexual orientation with data set did not affect the magnitude of the main effects of sexual orientation across all available data. That is, in men, the linear effect of sexual orientation on self-reported adulthood gender nonconformity remained similar in strength before and after controlling for this interaction, $p<.0001, \beta=.35[.28, .43]$, and $p<.0001, \beta=.33[.26, .40]$, respectively. This was also the case in women, $p<.0001, \beta=.42[.35, .49]$, and $p<.0001, \beta=$ $.42[.34, .50]$, respectively. This suggests that the overall effect of sexual orientation on gender nonconformity was not particularly driven by a specific data set.

\section{DISCUSSION}

In the present research, bisexual men and women had, in general, intermediate levels of gender nonconformity. We consider this finding consistent with Hypothesis 1A. This result mirrors the majority of previous findings that suggested that either by self-report, or by the views 
of others, bisexual men and women are intermediate (Burke \& LaFrance, 2016a; Cohen, 2002; Lippa, 2005, 2008, 2020). Hence, across past and present work, this intermediate level might be the most robust pattern regarding bisexual people's gender nonconformity.

There was no support for Hypothesis 1C, which was that bisexual individuals are closer to heterosexual than homosexual individuals in their gender nonconformity. Therefore, our findings did not correspond with a previous finding on how bisexual people view their own group (Burke \& LaFrance, 2016b). However, bisexual men were in most analyses (except for observer ratings) closer to homosexual men than heterosexual men. This is consistent with Hypothesis 1B. This latter finding corresponds with past work suggesting that some bisexualidentified men resemble homosexual men in their genital arousal and gender nonconformity (Rosenthal et al., 2012). Yet, one cannot simply conclude that most bisexual-identified men are equivalent to homosexual men. First, bisexual genital arousal is more common in bisexual men than heterosexual or homosexual men, even if it is rare and not always seen in individual samples (Rieger et al., 2015). Second, the present data did not suggest that bisexual men were equal to homosexual men in their gender nonconformity, but rather were between heterosexual and homosexual men, even for those measures where they were closer to homosexual than heterosexual men (Figs. 4B and 4C, Fig. 6A).

It is possible, though, that bisexual-identified individuals had, on a group level, intermediate levels of gender nonconformity between heterosexual and homosexual participants because they encompassed a combination of those who are heterosexual (and gender conforming) and homosexual (and gender nonconforming). In this case, we would have expected greater variability in the gender nonconformity of bisexual participants than heterosexual or homosexual participants, in accordance with Hypothesis 2. However, we found no evidence for 
this in women and no clear support for this in men (Figs. 9-11). For bisexual men, this lack of increased variability in gender nonconformity (as compared to both heterosexual and homosexual men) contrasts with the increased variation in their genital arousal, in which at least some are like heterosexual men but others like homosexual men (Slettevold et al., 2019).

Perhaps bisexual men and women simply are neither similar to heterosexual nor homosexual people in their gender nonconformity but, instead, are intermediate. We explored possible reasons for this finding. Most men are attracted to women and are more masculine than feminine, and most women are attracted to men and are more feminine than masculine (Lippa, 2005). If attraction to a specific sex links to a specific gender-typed trait, then individuals with attractions to both sexes could show increased masculinity in addition to increased femininity. However, at least with respect to observer ratings, we do not think that this was the case. For 228 targets, we had ratings that assessed their level of masculinity and, independently, their level of femininity. These two ratings were highly and negatively correlated, consistent with a definition of masculinity and femininity as two endpoints of a single dimension (Lippa, 2008). Moreover, both in their rated masculinity and their rated femininity, bisexual men and women were midway between heterosexual and homosexual participants, further supporting the hypothesis of their intermediate levels of gender nonconformity (Figs. 7 and 8).

Perhaps the reason for the intermediate stages of gender nonconformity of bisexual men and women start early in development. One proposal is that the development of homosexuality and gender nonconformity is affected by the relative dosage of crucial influences such as genetic variants or androgens (Bailey \& Pillard, 1991). If such dosage effects are gradual, rather than dependent on a certain threshold that switches from heterosexual to homosexual, then perhaps an intermediate dosage results in an intermediate sexual orientation, that is, bisexuality, and 
intermediate levels of masculinity and femininity. For instance, possibly due to an immunological reaction of mothers to Y-linked proteins of their first sons, mothers produce antibodies that disrupt the typical masculinization of their later sons, rendering them both more feminine and attracted to males (Bogaert et al., 2018). If such immunological reactions work gradually, subsequent sons may not be entirely feminized but remain somewhat masculinized and, in addition, not become entirely same-sex attracted but develop bisexual attractions. Other work points to the possibility of gradual dosage effects: Due to the mothers' immunological reactions to their earlier sons, homosexual men tend to have more older brothers than heterosexual men, but this proportion is even higher in (male-to-female) transgender women with attractions to males (Khorashad et al., 2020). Thus, depending on the dosage of the mothers' immunological reactions, the sons' gender identity could become female-typical in addition to their sexual orientation (Blanchard, 2018).

Further work suggests that men with decreased attractions to females reported less muscular physical features than other men, and women with increased attractions to females report more masculine features, possibly because dosage effects gradually influence sexual attraction and masculinization in both sexes (Ellis, Skorska, \& Bogaert, 2017). Social influences, such as the quality of relationships with others during childhood, could also come in different dosages and gradually affect both same-sex (versus other-sex) attraction and masculinityfemininity. However, in general, early social factors do not appear to influence the codevelopment of sexual orientation and gender-typed traits (Xu, Norton, \& Rahman, 2019).

Similar to the finding that bisexual men and women were between heterosexual and homosexual participants in their gender nonconformity, most analyses indicated a continuous increase of gender nonconformity from heterosexual to mostly heterosexual, to bisexual, to 
mostly homosexual, to homosexual. We consider this finding consistent with Hypothesis 3A. Moreover, it fits with the observation that mostly heterosexual and mostly homosexual individuals are somewhat different from exclusive groups in their psychological makeup or physiological sexual arousal, (Savin-Williams et al., 2013; Semon et al., 2017; Vrangalova \& Savin-Williams, 2012). Notably, mostly heterosexual men were closer to bisexual men than heterosexual men in their overall gender nonconformity (Fig. 6A). We note that this distinction between heterosexual and mostly heterosexual men becomes more obvious across measures of gender nonconformity if sexual orientation is used as a categorical variable (these findings can be obtained from the corresponding author). A similar pattern has been described for their physiological sexual arousal (Savin-Williams et al., 2013). Still, if past and present findings are taken together, mostly heterosexual men do not appear to be entirely equal to bisexual men either in their gender nonconformity or sexual arousal.

Another finding should be considered. Homosexual men and women were most variable in their gender nonconformity, which has been previously reported (Lippa, 2005, 2008). Multiple biological influences (e.g., genetic predisposition or maternal immunological reactions) could equally lead to a same-sex sexual orientation, but differently affect the expression of gendertyped traits. For these variable influences, same-sex attracted individuals could substantially vary in their masculinity-femininity (Swift-Gallant, Coome, Aitken, Monks, \& VanderLaan, 2019). A social explanation is also possible. Pressures to express stereotypical gender roles could cause some homosexual men and women to behave in gender-conforming ways; yet, counteractive influences within gay and lesbian communities compel others to express gender nonconformity. If we consider this hypothesis for present findings, these competing pressures to express conformity or nonconformity could act more on homosexual than on bisexual people. Because 
bisexual people have attractions to both sexes, they may be able to assimilate more easily than homosexual people with the heterosexual majority. Thus, for bisexual individuals, social pressures may be more one-sided towards the gender norms of the majority, resulting in less variability in their masculinity-femininity.

A broad limitation of our research was that study volunteers tended to live in liberaloriented locations in North America and Europe and were willing to come to the lab. Because of these self-selection biases, we cannot claim that reported findings are representative of the general population. Although age, ethnicity, and education did not appear influential in our results, there may be other unknown or unassessed factors that did. Finally, although sexual orientation tends to be a stable trait, bisexual individuals report more temporal changes in their sexual orientation than other individuals (Savin-Williams, Joyner, \& Rieger, 2012). For this reason, reported patterns between sexual orientation and gender nonconformity might appear different if participants had been followed over time.

In conclusion, it is possible that men and women with nonexclusive sexual orientations are not entirely similar to either heterosexual or homosexual people in their gender nonconformity. To date, there is no definite explanation as to why this is the case. Still, the present findings suggest that men and women with varied degrees of bisexual attractions should neither be simply grouped together nor should any one subgroup be simply equaled with being heterosexual or homosexual. Rather, men and women with varied attractions towards both sexes likely fall on a continuum from heterosexual to homosexual, at least with respect to their gendertyped expressions. 


\section{NOTES}

\section{Funding}

This research was funded by the American Institute of Bisexuality (RSC1466) and the University of Essex (DG00832).

\section{Compliance with Ethical Standards}

The University of Essex’s Ethics Committee approved this study (GR1303).

\section{Conflict of Interest}

All authors declare that they have no conflict of interest.

\section{Ethical Approval}

All procedures performed in studies involving human participants were in accordance with the ethical standards of the institutional committee and with the 1964 Helsinki declaration and its later amendments or comparable ethical standards.

\section{Informed Consent}

Informed consent was obtained from all individual participants included in the study. 


\section{REFERENCES}

Bailey, J. M. (2009). What is sexual orientation and do women have one? In D. A. Hope (Ed.), Contemporary perspectives on lesbian, gay, and bisexual identities (Vol. 54, pp. 43-63). New York, NY: Springer.

Bailey, J. M., \& Pillard, R. C. (1991). A genetic study of male sexual orientation. Archives of General Psychiatry, 48, 1089-1096. doi:10.1001/archpsyc.1991.01810360053008

Bailey, J. M., \& Zucker, K. J. (1995). Childhood sex-typed behavior and sexual orientation: A conceptual analysis and quantitative review. Developmental Psychology, 31, 43-55. doi:10.1037/0012-1649.31.1.43

Blanchard, R. (2018). Fraternal birth order, family size, and male homosexuality: Meta-analysis of studies spanning 25 years. Archives of Sexual Behavior, 47, 1-15. doi:10.1007/s10508$017-1007-4$

Bogaert, A. F., Skorska, M. N., Wang, C., Gabrie, J., MacNeil, A. J., Hoffarth, M. R., . . Blanchard, R. (2018). Male homosexuality and maternal immune responsivity to the Ylinked protein NLGN4Y. Proceedings of the National Academy of Sciences, 115, 302. doi:10.1073/pnas.1705895114

Burke, S. E., \& LaFrance, M. (2016a). Lay conceptions of sexual minority groups. Archives of Sexual Behavior, 45, 635-650. doi:10.1007/s10508-015-0655-5

Burke, S. E., \& LaFrance, M. (2016b). Stereotypes of bisexual people: What do bisexual people themselves think? Psychology of Sexual Orientation and Gender Diversity, 3, 247-254. doi:10.1037/sgd0000168 
Chivers, M. L. (2017). The specificity of women's sexual response and its relationship with sexual orientations: A review and ten hypotheses. Archives of Sexual Behavior, 46, 11611179. doi:10.1007/s10508-016-0897-x

Cohen, K. M. (2002). Relationships among childhood sex-atypical behavior, spatial ability, handedness, and sexual orientation in men. Archives of Sexual Behavior, 31, 129-143. doi:10.1023/a:1014043504661

Ellis, L., Skorska, M. N., \& Bogaert, A. F. (2017). Handedness, sexual orientation, and somatic markers for prenatal androgens: Are southpaws really that gay? Laterality: Asymmetries of Body, Brain and Cognition, 22, 157-180. doi:10.1080/1357650X.2016.1151024

Gottschalk, L. (2003). Same-sex sexuality and childhood gender non-conformity: A spurious connection. Journal of Gender Studies, 12, 35-50. doi:10.1080/0958923032000067808

Hsu, K. J., Rosenthal, A. M., Miller, D. I., \& Bailey, J. M. (2016). Who are gynandromorphophilic men? Characterizing men with sexual interest in transgender women. Psychological Medicine, 46, 819-827. doi:10.1017/S0033291715002317

Jabbour, J., Hsu, K. J., \& Bailey, J. M. (2020). Sexual arousal patterns of mostly heterosexual men. Archives of Sexual Behavior. doi:10.1007/s10508-020-01720-z

Johnson, K. L., Gill, S., Reichman, V., \& Tassinary, L. G. (2007). Swagger, sway, and sexuality: Judging sexual orientation from body motion and morphology. Journal of Personality and Social Psychology, 93, 321-334. doi:10.1037/0022-3514.93.3.321

Kahn, N. F., \& Halpern, C. T. (2019). Is developmental change in gender-typed behavior associated with adult sexual orientation? Developmental Psychology, 55, 855-865. doi:10.1037/dev0000662 
Khorashad, B. S., Zucker, K. J., Talaei, A., Rajabzadeh, F., Hamed, Z., Akbarian, P., \& Blanchard, R. (2020). Birth order and sibling sex ratio in androphilic males and gynephilic females diagnosed with gender dysphoria from Iran. The Journal of Sexual Medicine. doi:10.1016/j.jsxm.2020.02.004

Kinsey, A. C., Pomeroy, W. B., \& Martin, C. E. (1948). Sexual behavior in the human male. Philadelphia, PA: W. B. Saunders.

Lippa, R. A. (2005). Sexual orientation and personality. Annual Review of Sex Research, 16, 119-153. doi:10.1080/10532528.2005.10559831

Lippa, R. A. (2008). Sex differences and sexual orientation differences in personality: Findings from the BBC Internet survey. Archives of Sexual Behavior, 37, 173-187. doi:10.1007/s10508-007-9267-z

Lippa, R. A. (2020). Interest, personality, and sexual traits that distinguish heterosexual, bisexual, and homosexual individuals: Are there two dimensions that underlie variations in sexual orientation? Archives of Sexual Behavior. doi:10.1007/s10508-020-01643-9

Rieger, G., Cash, B. M., Merrill, S. M., Jones-Rounds, J., Dharmavaram, S. M., \& SavinWilliams, R. C. (2015). Sexual arousal: The correspondence of eyes and genitals. Biological Psychology, 104, 56-64. doi:10.1016/j.biopsycho.2014.11.009

Rieger, G., Chivers, M. L., \& Bailey, J. M. (2005). Sexual arousal patterns of bisexual men. Psychological Science, 16, 579-584. doi:10.1111/j.1467-9280.2005.01578.x

Rieger, G., Linsenmeier, J. A. W., Gygax, L., \& Bailey, J. M. (2008). Sexual orientation and childhood gender nonconformity: Evidence from home videos. Developmental Psychology, 44, 46-58. doi:10.1037/0012-1649.44.1.46 
Rieger, G., Linsenmeier, J. A. W., Gygax, L., Garcia, S. C., \& Bailey, J. M. (2010). Dissecting "gaydar": Accuracy and the role of masculinity-femininity. Archives of Sexual Behavior, 39, 124-140. doi:10.1007/s10508-008-9405-2

Rieger, G., Savin-Williams, R. C., Chivers, M. L., \& Bailey, J. M. (2016). Sexual arousal and masculinity-femininity of women. Journal of Personality and Social Psychology, 111, 265-283. doi:10.1037/pspp0000077

Rosenthal, A. M., Sylva, D., Safron, A., \& Bailey, J. M. (2012). The male bisexuality debate revisited: Some bisexual men have bisexual arousal patterns. Archives of Sexual Behavior, 41, 135-147. doi:10.1007/s10508-011-9881-7

Savin-Williams, R. C., Cash, B. M., McCormack, M., \& Rieger, G. (2017). Gay, mostly gay, or bisexual leaning gay? An exploratory study distinguishing gay sexual orientations among young men. Archives of Sexual Behavior, 46, 265-272. doi:10.1007/s10508-016-0848-6

Savin-Williams, R. C., Joyner, K., \& Rieger, G. (2012). Prevalence and stability of self-reported sexual orientation identity during young adulthood. Archives of Sexual Behavior, 41, 103110. doi:10.1007/s10508-012-9913-y

Savin-Williams, R. C., Rieger, G., \& Rosenthal, A. M. (2013). Physiological evidence for a mostly heterosexual orientation among men. Archives of Sexual Behavior, 42, 697-699. doi:10.1007/s10508-013-0093-1

Savin-Williams, R. C., \& Vrangalova, Z. (2013). Mostly heterosexual as a distinct sexual orientation group: A systematic review of the empirical evidence. Developmental Review, 33, 58-88. doi:10.1016/j.dr.2013.01.001 
Semon, T. L., Hsu, K. J., Rosenthal, A. M., \& Bailey, J. M. (2017). Bisexual phenomena among gay-identified men. Archives of Sexual Behavior, 46, 237-245. doi:10.1007/s10508-016$0849-5$

Slettevold, E., Holmes, L., Gruia, D., Nyssen, C. P., Watts-Overall, T. M., \& Rieger, G. (2019). Bisexual men with bisexual and monosexual genital arousal patterns. Biological Psychology, 148, 107763. doi:10.1016/j.biopsycho.2019.107763

Swift-Gallant, A., Coome, L. A., Aitken, M., Monks, D. A., \& VanderLaan, D. P. (2019). Evidence for distinct biodevelopmental influences on male sexual orientation. Proceedings of the National Academy of Sciences, 201809920. doi:10.1073/pnas.1809920116

Tskhay, K. O., \& Rule, N. O. (2013). Accuracy in categorizing perceptually ambiguous groups: A review and meta-analysis. Personality and Social Psychology Review, 17, 72-86. doi:Doi 10.1177/1088868312461308

Vrangalova, Z., \& Savin-Williams, R. (2012). Mostly heterosexual and mostly gay/lesbian: Evidence for new sexual orientation identities. Archives of Sexual Behavior, 41, 85-101. doi:10.1007/s10508-012-9921-y

Xu, Y., Norton, S., \& Rahman, Q. (2019). Early life conditions and adolescent sexual orientation: A prospective birth cohort study. Developmental Psychology, 55 1226-1243. doi:10.1037/dev0000704

Zucker, K. J. (2005). Commentary on Gottschalk's (2003) 'Same-sex sexuality and childhood gender non-conformity: A spurious connection'. Journal of Gender Studies, 14, 55-60. doi:10.1080/0958923042000331498 
Table 1.

Distribution of Sexual Orientation Identities across Age and Ethnicities.

\begin{tabular}{|c|c|c|c|c|c|c|c|}
\hline $\operatorname{Men}(N=654)$ & $\begin{array}{l}\text { 0) Exclusively } \\
\text { Heterosexual }\end{array}$ & $\begin{array}{c}\text { 1) Mostly } \\
\text { Heterosexual }\end{array}$ & $\begin{array}{l}\text { 2) Bisexual } \\
\text { Leaning } \\
\text { Heterosexual }\end{array}$ & 3) Bisexual & $\begin{array}{l}\text { 4) Bisexual } \\
\text { Leaning } \\
\text { Homosexual }\end{array}$ & $\begin{array}{l}\text { 5) Mostly } \\
\text { Homosexual }\end{array}$ & $\begin{array}{l}\text { 6) Exclusively } \\
\text { Homosexual }\end{array}$ \\
\hline Number & 170 & 83 & 59 & 37 & 64 & 108 & 133 \\
\hline Average Age & $\begin{array}{c}23.99 \\
{[22.79,25.19]}\end{array}$ & $\begin{array}{c}26.11 \\
{[24.40,27.82]}\end{array}$ & $\begin{array}{c}28.81 \\
{[26.78,30.84]}\end{array}$ & $\begin{array}{c}28.32 \\
{[25.76,30.89]}\end{array}$ & $\begin{array}{c}26.05 \\
{[24.10,28.00]}\end{array}$ & $\begin{array}{c}24.58 \\
{[23.08,26.09]}\end{array}$ & $\begin{array}{c}25.86 \\
{[24.50,27.21]}\end{array}$ \\
\hline Percentage Caucasian ${ }^{1}$ & $\begin{array}{c}70 \\
{[63,77]}\end{array}$ & $\begin{array}{c}77 \\
{[66,85]}\end{array}$ & $\begin{array}{c}74 \\
{[60,84]}\end{array}$ & $\begin{array}{c}66 \\
{[47,80]}\end{array}$ & $\begin{array}{c}50 \\
{[37,63]}\end{array}$ & $\begin{array}{c}69 \\
{[59,77]}\end{array}$ & $\begin{array}{c}71 \\
{[62,79]}\end{array}$ \\
\hline Average Education ${ }^{2}$ & $\begin{array}{c}4.31 \\
{[4.15,4.47]}\end{array}$ & $\begin{array}{c}4.49 \\
{[4.30,4.69]}\end{array}$ & $\begin{array}{c}4.50 \\
{[4.23,4.77]}\end{array}$ & $\begin{array}{c}4.85 \\
{[4.49,5.21]}\end{array}$ & $\begin{array}{c}4.58 \\
{[4.35,4.81]}\end{array}$ & $\begin{array}{c}4.59 \\
{[4.39,4.78]}\end{array}$ & $\begin{array}{c}4.73 \\
{[4.53,4.92]}\end{array}$ \\
\hline Women $(\mathrm{N}=611)$ & $\begin{array}{l}\text { 0) Exclusively } \\
\text { Heterosexual }\end{array}$ & $\begin{array}{c}\text { 1) Mostly } \\
\text { Heterosexual }\end{array}$ & $\begin{array}{l}\text { 2) Bisexual } \\
\text { Leaning } \\
\text { Heterosexual }\end{array}$ & 3) Bisexual & $\begin{array}{l}\text { 4) Bisexual } \\
\text { Leaning } \\
\text { Homosexual }\end{array}$ & $\begin{array}{c}\text { 5) Mostly } \\
\text { Homosexual }\end{array}$ & $\begin{array}{l}\text { 6) Exclusively } \\
\text { Homosexual }\end{array}$ \\
\hline Number & 121 & 117 & 73 & 60 & 60 & 106 & 74 \\
\hline Average Age & $\begin{array}{c}22.52 \\
{[21.51,23.53]}\end{array}$ & $\begin{array}{c}22.85 \\
{[22.11,23.60]}\end{array}$ & $\begin{array}{c}23.14 \\
{[22.20,24.07]}\end{array}$ & $\begin{array}{c}22.93 \\
{[21.58,24.29]}\end{array}$ & $\begin{array}{c}23.12 \\
{[21.76,24.48]}\end{array}$ & $\begin{array}{c}24.54 \\
{[23.25,25.82]}\end{array}$ & $\begin{array}{c}24.30 \\
{[23.15,25.45]}\end{array}$ \\
\hline Percentage Caucasian $^{1}$ & $\begin{array}{c}61 \\
{[52,69]}\end{array}$ & $\begin{array}{c}69 \\
{[60,77]}\end{array}$ & $\begin{array}{c}62 \\
{[50,72]}\end{array}$ & $\begin{array}{c}67 \\
{[54,77]}\end{array}$ & $\begin{array}{c}65 \\
{[52,76]}\end{array}$ & $\begin{array}{c}74 \\
{[64,81]}\end{array}$ & $\begin{array}{c}80 \\
{[70,87]}\end{array}$ \\
\hline Average Education ${ }^{2}$ & $\begin{array}{c}4.09 \\
{[3.91,4.27]}\end{array}$ & $\begin{array}{c}4.48 \\
{[4.28,4.68]}\end{array}$ & $\begin{array}{c}4.56 \\
{[4.34,4.77]}\end{array}$ & $\begin{array}{c}4.67 \\
{[4.33,5.00]}\end{array}$ & $\begin{array}{c}4.36 \\
{[4.11,4.62]}\end{array}$ & $\begin{array}{c}4.72 \\
{[4.54,4.89]}\end{array}$ & $\begin{array}{c}4.52 \\
{[4.25,4.80]}\end{array}$ \\
\hline
\end{tabular}

Note. Brackets show 95\% confidence intervals. ${ }^{1}$ Three other most common ethnicities across sexes were Black (8\%), Hispanic (7\%), and Asian (4\%).

${ }^{2}$ Coded as 1 (no high school), 2 (some high school), 3 (high school diploma), 4 (some college), 5 (college graduate), 6 (postgraduate student or degree). 
Fig. 1. Hypothetical degree of gender nonconformity. Reported sexual orientation in relation to gender nonconformity if (A) bisexual individuals were between heterosexual and homosexual individuals; if (B) bisexual individuals were similar to homosexual individuals and different from heterosexual individuals; if (C) bisexual individuals were similar to heterosexual individuals and different from homosexual individuals. On the $\mathrm{Y}$ axes, 1 is most gender conforming, 4 is average, and 7 is most gender nonconforming. On the $\mathrm{X}$ axes, 0 is exclusively heterosexual, 1 mostly heterosexual, 2 bisexual leaning heterosexual, 3 bisexual with equal preferences, 4 bisexual leaning homosexual, 5 mostly homosexual, and 6 exclusively homosexual.

Fig. 2. Hypothetical degree of gender nonconformity. Reported sexual orientation in relation to variation in gender nonconformity if bisexual individuals were more variant than heterosexual and homosexual individuals. On the Y axis, higher scores represent more variation in gender nonconformity. On the $\mathrm{X}$ axis, 0 is exclusively heterosexual, 1 mostly heterosexual, 2 bisexual leaning heterosexual, 3 bisexual with equal preferences, 4 bisexual leaning homosexual, 5 mostly homosexual, and 6 exclusively homosexual. 
Fig. 3. Hypothetical degree of gender nonconformity. Reported sexual orientation in relation to gender nonconformity if (A) mostly heterosexual individuals are between heterosexual and bisexual, and mostly homosexual individuals are between bisexual and homosexual; if (B) mostly heterosexual and mostly homosexual individuals were similar to bisexual individuals; if (C) heterosexual and mostly heterosexual individuals were similar, and homosexual and mostly homosexual individuals were similar. On the Y axes, 1 is most gender conforming, 4 is average, and 7 is most gender nonconforming. On the $\mathrm{X}$ axes, 0 is exclusively heterosexual, 1 mostly heterosexual, 2 bisexual leaning heterosexual, 3 bisexual with equal preferences, 4 bisexual leaning homosexual, 5 mostly homosexual, and 6 exclusively homosexual.

Fig. 4. Men's degree of gender nonconformity. Reported sexual orientation in relation to gender nonconformity for self-report from childhood $(n=525 ; \mathrm{A})$ and adulthood $(n=654 ; \mathrm{B})$, and observer ratings in adulthood $(n=457 ; \mathrm{C})$. On the $\mathrm{Y}$ axes, 1 is most masculine, 4 is average, and 7 is most feminine. On the $\mathrm{X}$ axes, 0 is exclusively heterosexual, 1 mostly heterosexual, 3 bisexual with equal preferences, 5 mostly homosexual, and 6 exclusively homosexual. Triple lines are regression coefficients with $95 \%$ confidence intervals. Vertical lines show stationary points of significant curvilinear effects. Dots are participants' average scores. Statistics represent linear, curvilinear, and cubic effects. 
Fig. 5. Women's degree of gender nonconformity. Reported sexual orientation in relation to gender nonconformity for self-report from childhood $(n=394 ; \mathrm{A})$ and adulthood $(n=611 ; \mathrm{B})$, and observer ratings in adulthood $(n=458 ; \mathrm{C})$. On the $\mathrm{Y}$ axes, 1 is most feminine, 4 is average, and 7 is most masculine. On the $\mathrm{X}$ axes, 0 is exclusively heterosexual, 1 mostly heterosexual, 3 bisexual with equal preferences, 5 mostly homosexual, and 6 exclusively homosexual. Triple lines are regression coefficients with $95 \%$ confidence intervals. Vertical lines show stationary points of significant curvilinear effects. Dots are participants' average scores. Statistics represent linear, curvilinear, and cubic effects.

Fig. 6. Overall degree of gender nonconformity. Reported sexual orientation in relation to a composite score of gender nonconformity across measures for 291 men (A) and 297 women (B). On the Y axes, 1 is most gender conforming, 4 is average, and 7 is most gender nonconforming. On the $\mathrm{X}$ axes, 0 is exclusively heterosexual, 1 mostly heterosexual, 3 bisexual with equal preferences, 5 mostly homosexual, and 6 exclusively homosexual. Triple lines are regression coefficients with $95 \%$ confidence intervals. Dots are participants' average scores. Statistics represent linear, curvilinear, and cubic effects. 
Fig. 7. Men's degree of masculinity and femininity. Reported sexual orientation in relation to observer-rated adulthood masculinity $(n$

$=114 ; \mathrm{A})$ and observer-rated adulthood femininity $(n=114 ; \mathrm{B})$. On the $\mathrm{Y}$ axes, 1 is the lowest score, 4 is average, and 7 is the highest score on each measure. On the $\mathrm{X}$ axes, 0 is exclusively heterosexual, 1 mostly heterosexual, 3 bisexual with equal preferences, 5 mostly homosexual, and 6 exclusively homosexual. Triple lines are regression coefficients with $95 \%$ confidence intervals. Dots are participants' average scores. Statistics represent linear, curvilinear, and cubic effects.

Fig. 8. Women's degree of masculinity and femininity. Reported sexual orientation in relation to observer-rated adulthood masculinity $(n=114 ; \mathrm{A})$ and observer-rated adulthood femininity $(n=114 ; \mathrm{B})$. On the Y axes, 1 is the lowest score, 4 is average, and 7 is the highest score on each measure. On the $\mathrm{X}$ axes, 0 is exclusively heterosexual, 1 mostly heterosexual, 3 bisexual with equal preferences, 5 mostly homosexual, and 6 exclusively homosexual. Triple lines are regression coefficients with 95\% confidence intervals. Dots are participants' average scores. Statistics represent linear, curvilinear, and cubic effects. 
Fig. 9. Men's degree of gender nonconformity. Reported sexual orientation in relation to the absolute residuals derived from the effect displayed in Fig. 4 for self-report from childhood $(n=525$; A) and adulthood $(n=654$; B), and observer ratings in adulthood $(n=$ 457 ; C). On the $\mathrm{Y}$ axes, higher scores indicate greater variability. On the $\mathrm{X}$ axes, 0 is exclusively heterosexual, 1 mostly heterosexual, 3 bisexual with equal preferences, 5 mostly homosexual, and 6 exclusively homosexual. Triple lines are regression coefficients with 95\% confidence intervals. Vertical lines show stationary points of significant curvilinear effects. Dots are participants' average scores. Statistics represent linear, curvilinear, and cubic effects.

Fig. 10. Women's degree of gender nonconformity. Reported sexual orientation in relation to the absolute residuals derived from the effect displayed in Fig. 5 for self-report from childhood $(n=394 ; \mathrm{A})$ and adulthood $(n=611$; B), and observer ratings in adulthood ( $n$ $=458 ; \mathrm{C}$ ). On the $\mathrm{Y}$ axes, higher scores indicate greater variability. On the $\mathrm{X}$ axes, 0 is exclusively heterosexual, 1 mostly heterosexual, 3 bisexual with equal preferences, 5 mostly homosexual, and 6 exclusively homosexual. Triple lines are regression coefficients with 95\% confidence intervals. Vertical lines show stationary points of significant curvilinear effects. Dots are participants' average scores. Statistics represent linear, curvilinear, and cubic effects. 
Fig. 11. Overall degree of gender nonconformity. Reported sexual orientation in relation to the absolute residuals derived from the effect displayed in Fig. 6 for 291 men (A) and 297 women (B). On the Y axes, higher scores indicate greater variability. On the X axes, 0 is exclusively heterosexual, 1 mostly heterosexual, 3 bisexual with equal preferences, 5 mostly homosexual, and 6 exclusively homosexual. Triple lines are regression coefficients with $95 \%$ confidence intervals. Vertical lines show stationary points of significant curvilinear effects. Dots are participants' average scores. Statistics represent linear, curvilinear, and cubic effects. 

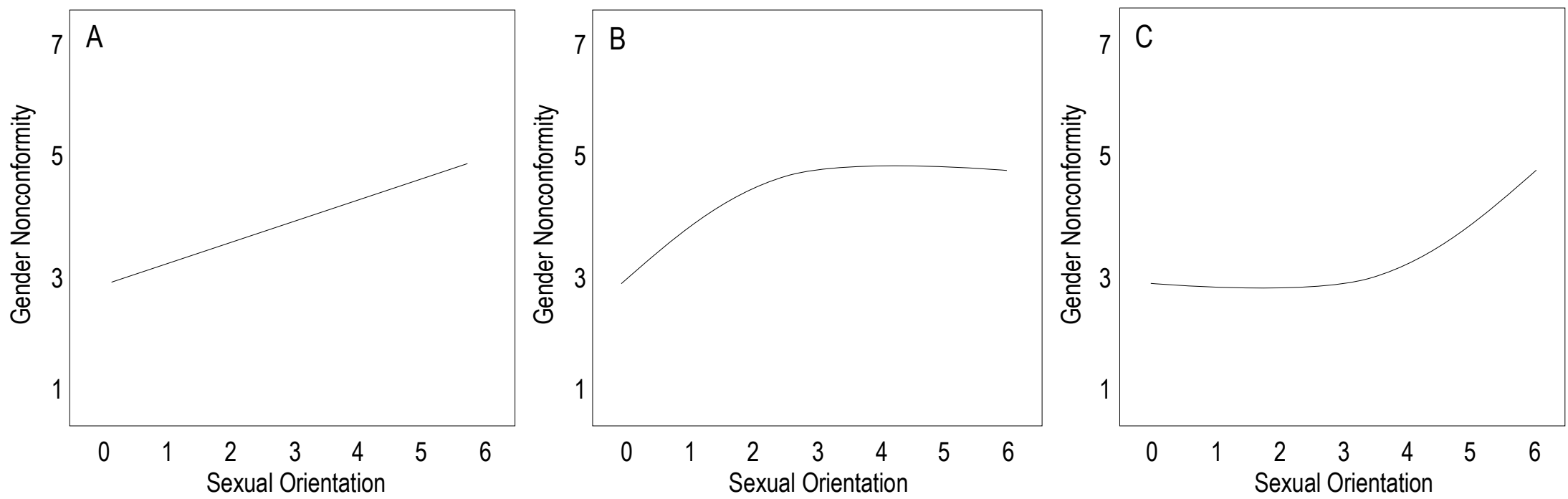

Fig. 1. 


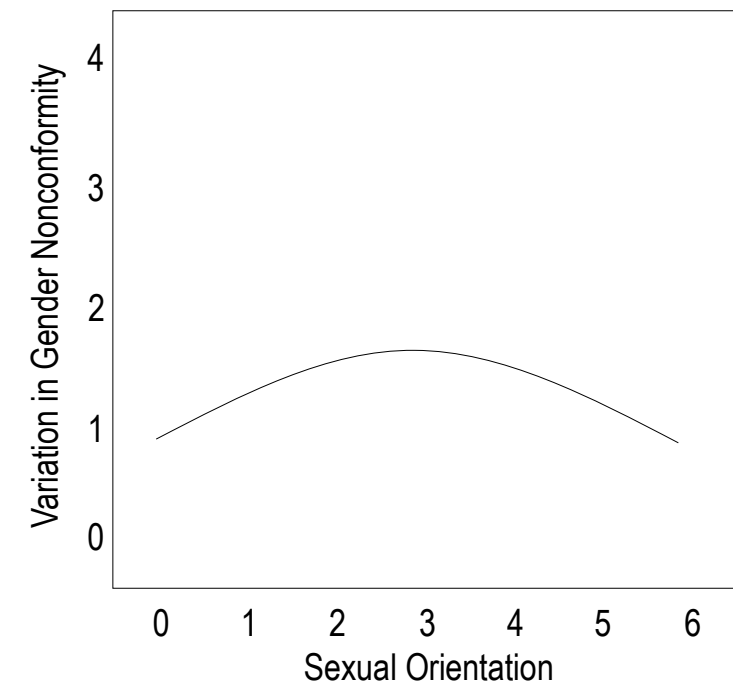

Fig. 2. 
40
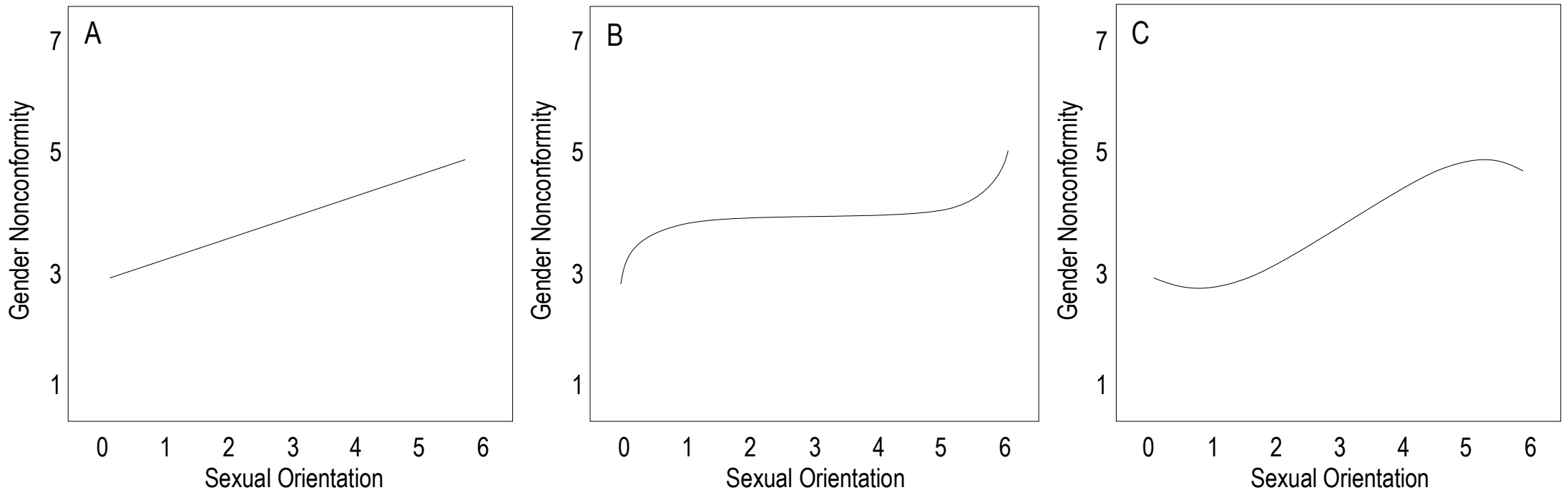

Fig. 3. 

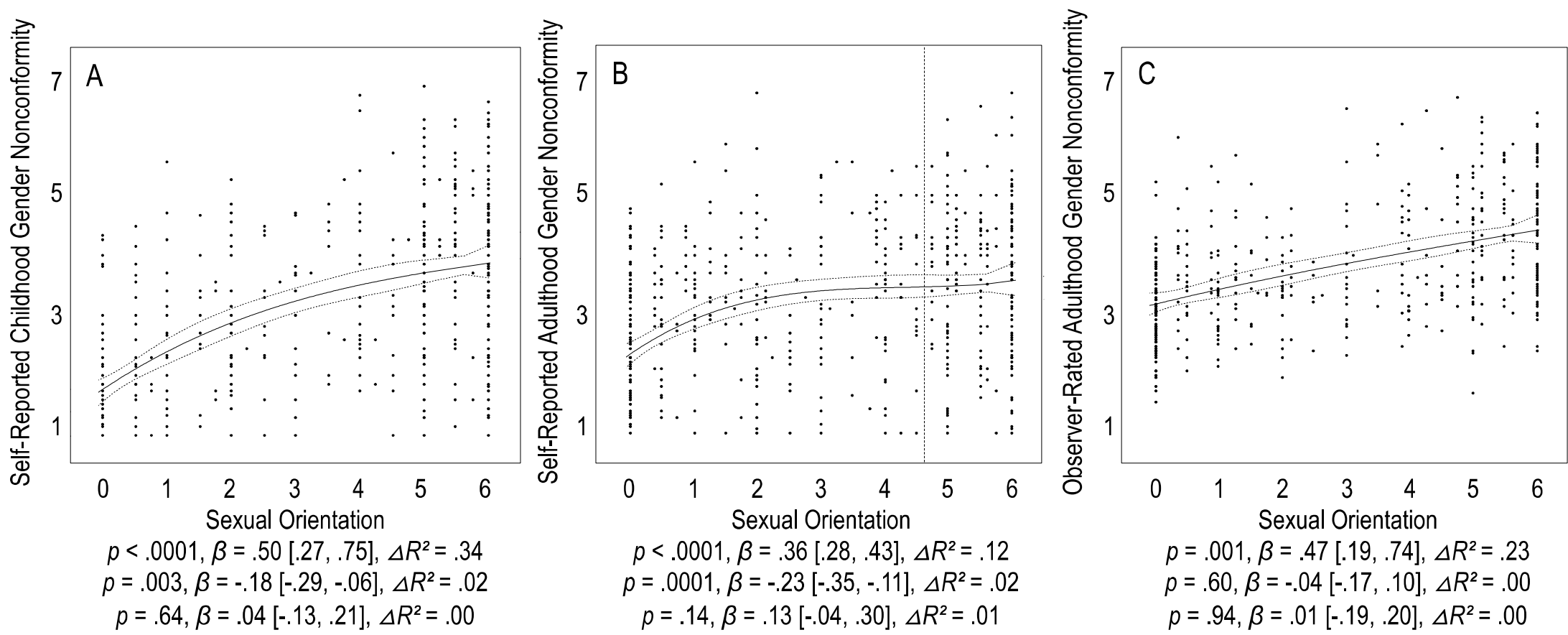

Fig. 4. 

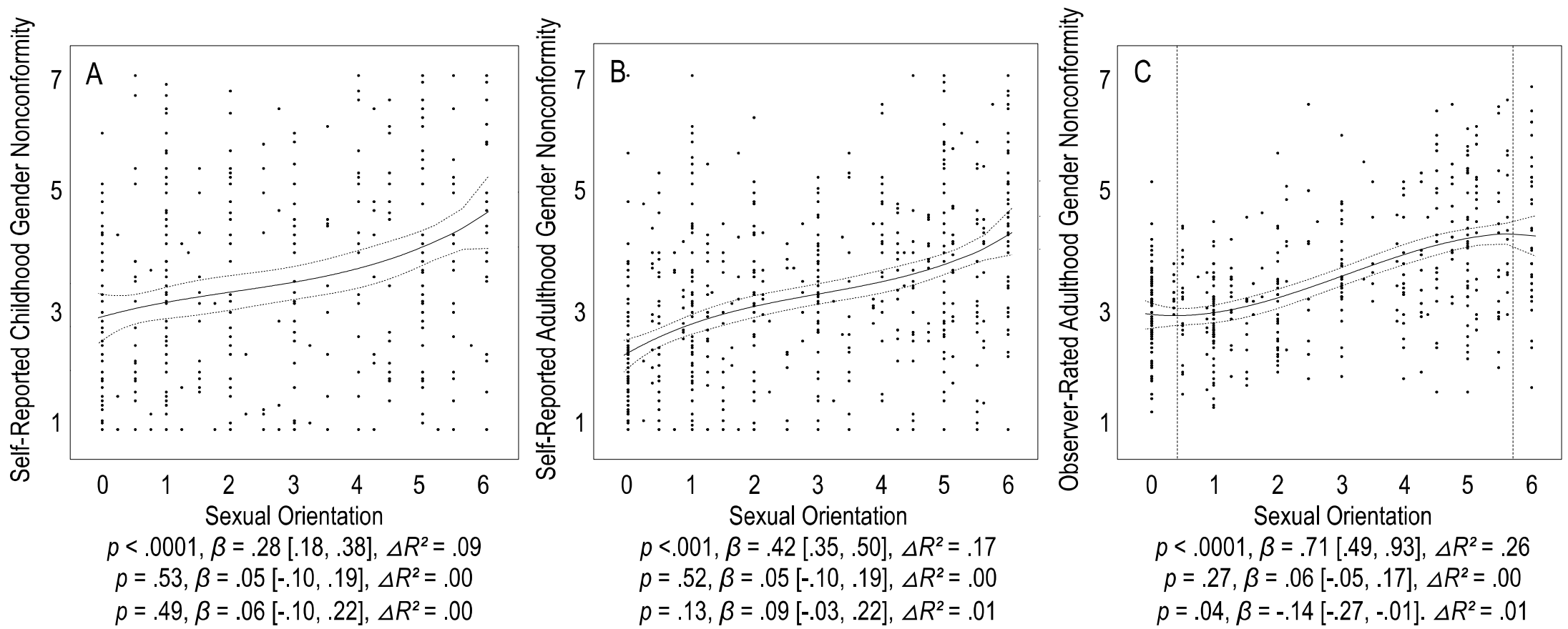

Fig. 5. 

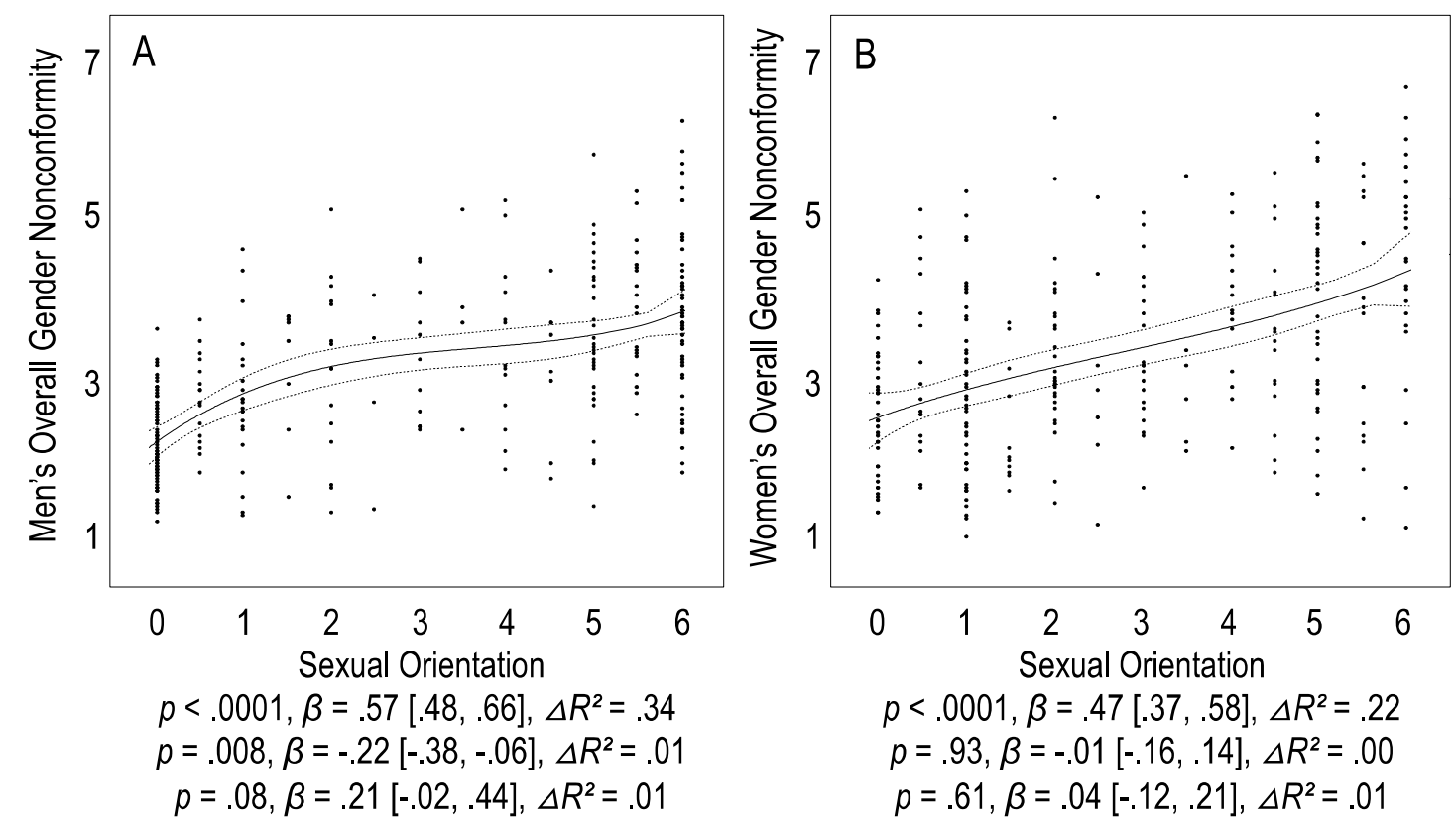

Fig. 6. 

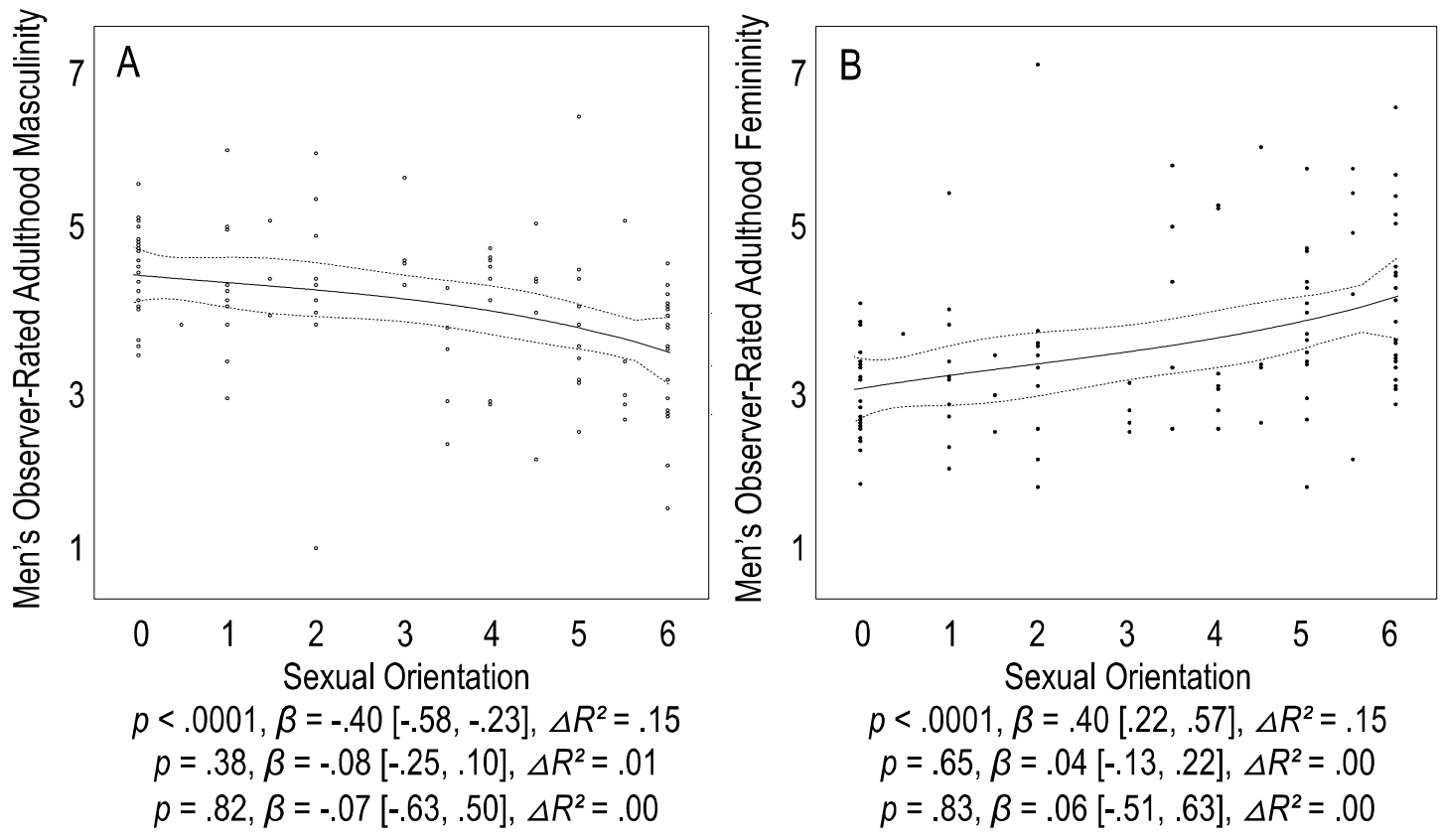

Fig. 7. 

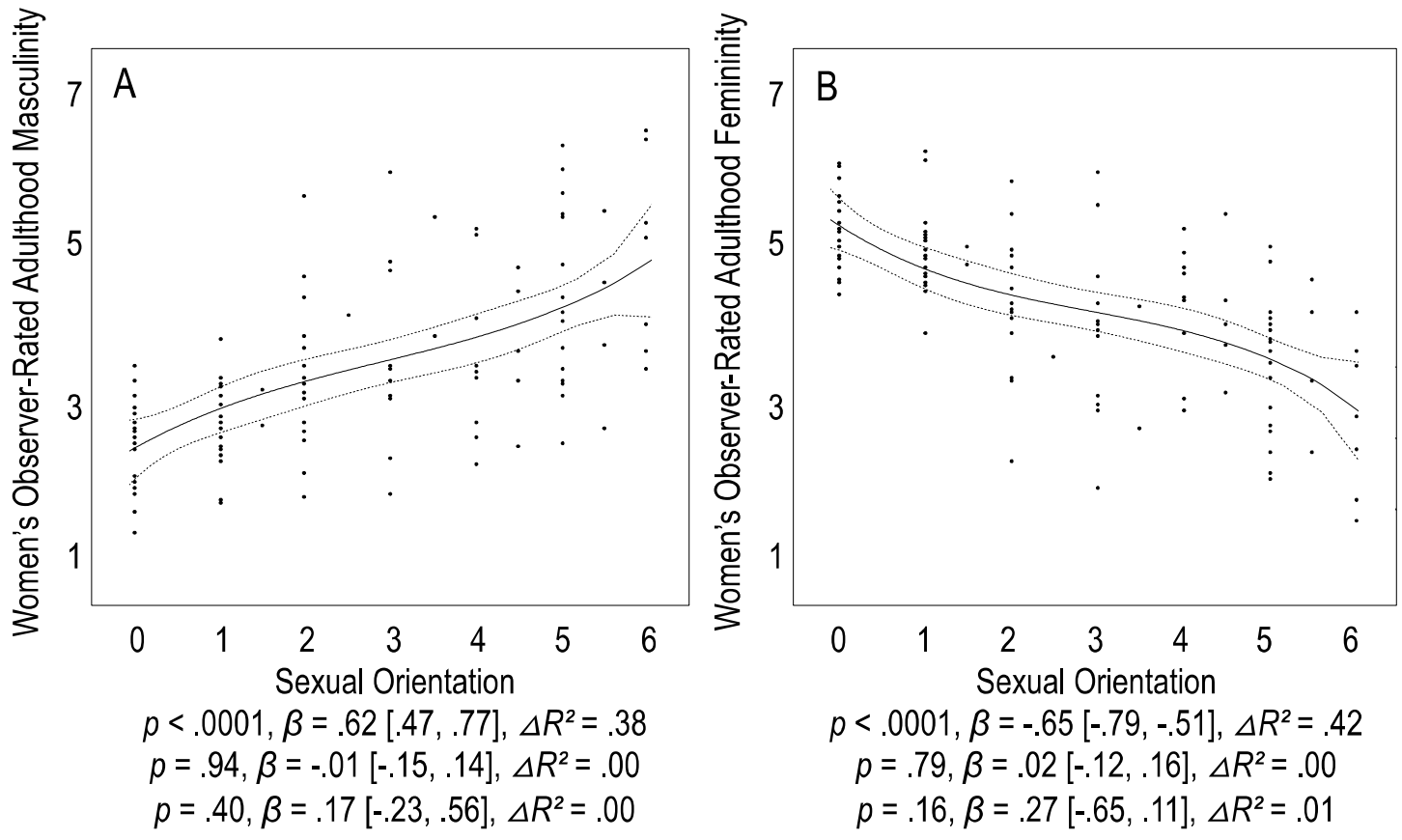

Fig. 8. 

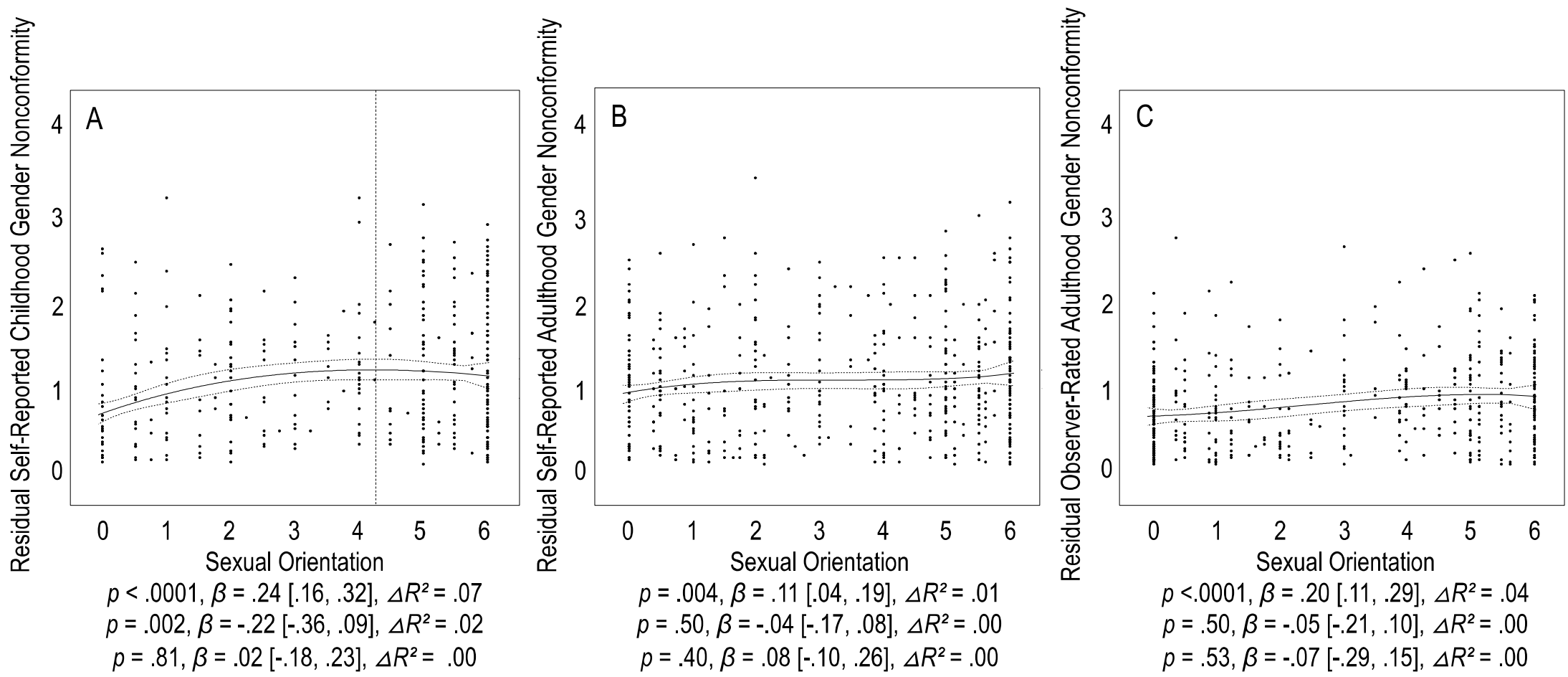

Fig. 9. 

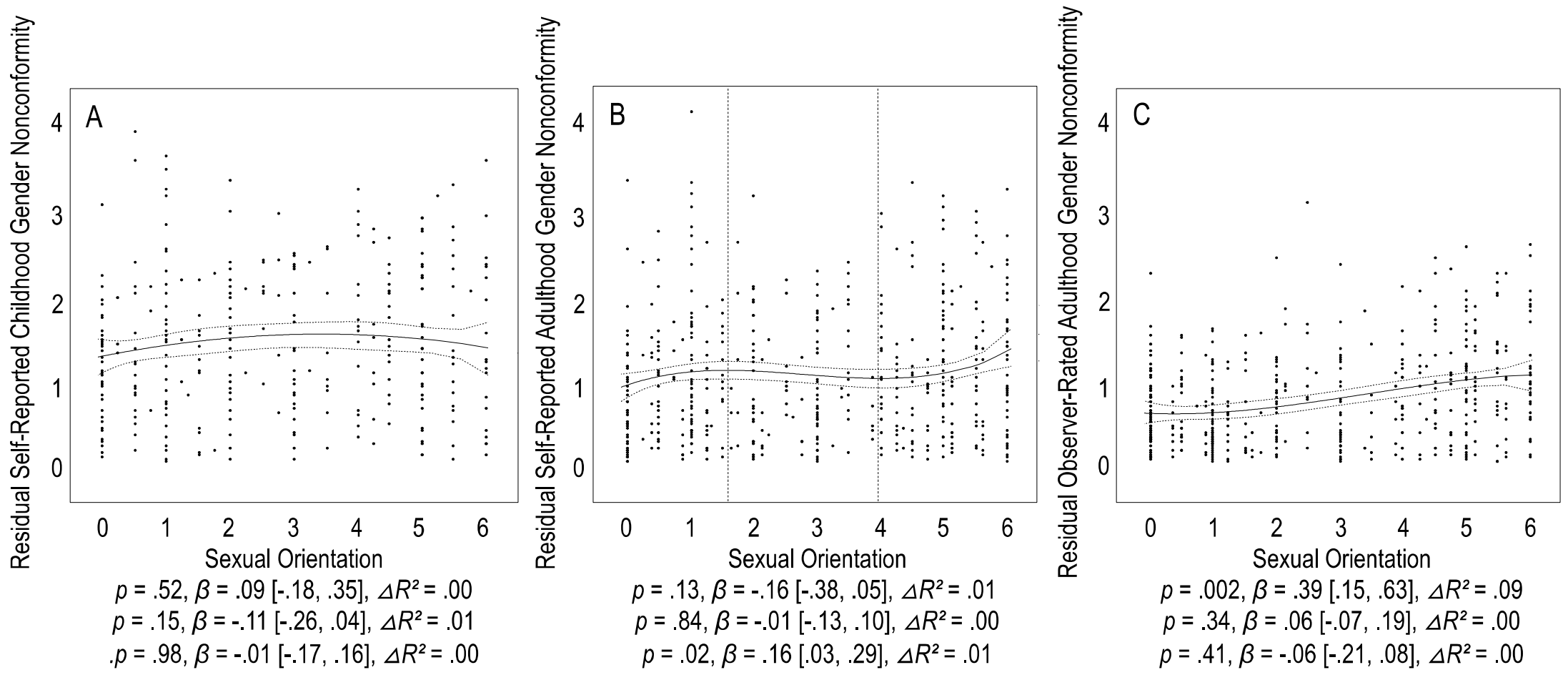

Fig. 10. 

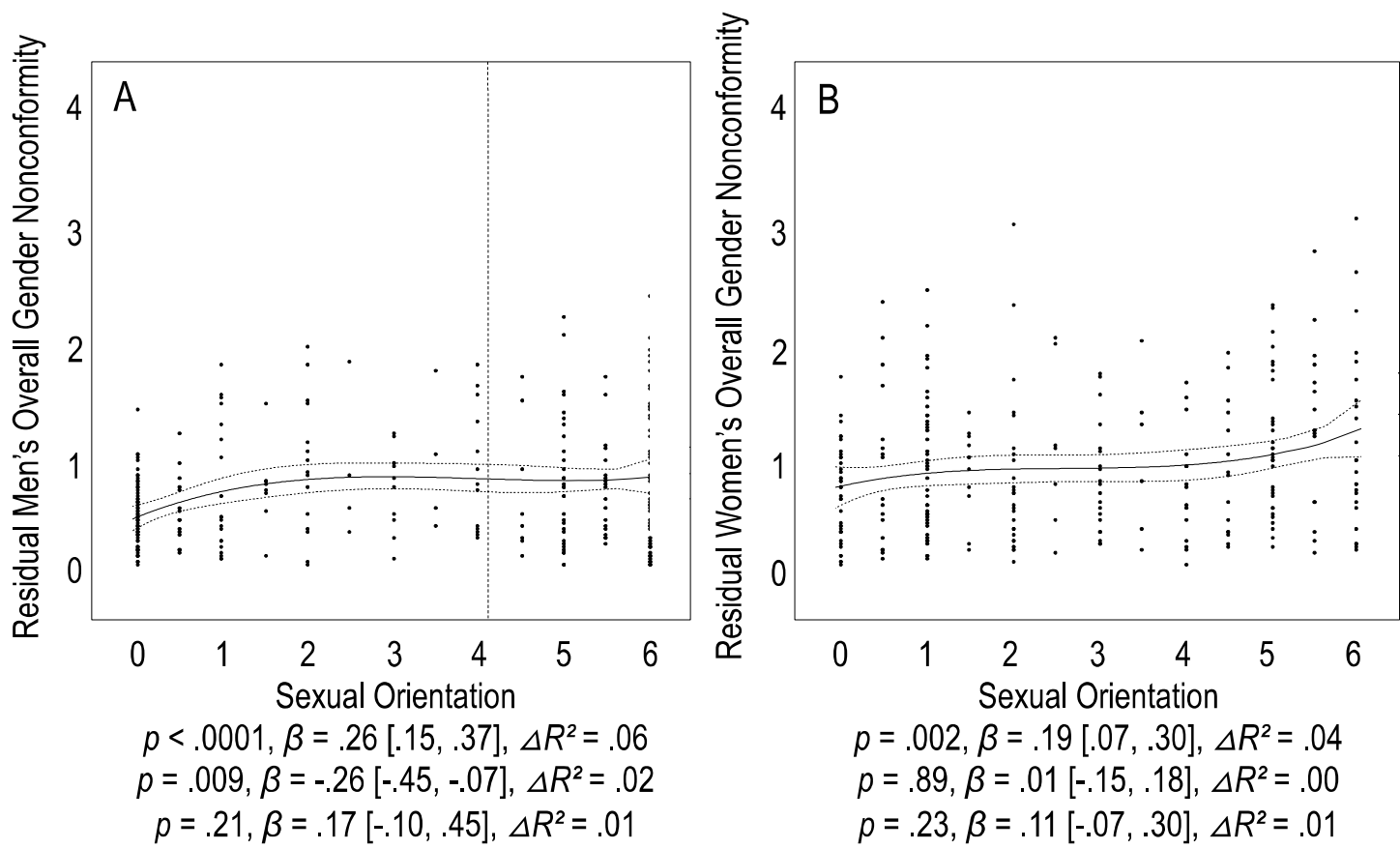

Fig. 11. 